\title{
In vitro effects of tropisetron and granisetron against Echinococcus granulosus (s.s.) protoscoleces by involvement of calcineurin and calmodulin
}

Mohammad Reza Shiee ${ }^{1}$, Eshrat Beigom Kia ${ }^{1 *}$, Farzaneh Zahabiun ${ }^{1}$, Mahmood Naderi ${ }^{2}$, Elahe Motevaseli ${ }^{3}$, Shahram Nekoeian ${ }^{3}$, Majid Fasihi Harandi ${ }^{4}$ and Ahmad Reza Dehpour ${ }^{5,6^{*}}$

\begin{abstract}
Background: Cystic echinococcosis (CE) is a disease caused by the larval stage of Echinococcus granulosus sensu lato (s.l.). The treatment of CE mainly relies on the use of benzimidazoles, which can commonly cause adverse side effects. Therefore, more efficient treatment options are needed. Drug repurposing is a useful approach for advancing drug development. We have evaluated the in vitro protoscolicidal effects of tropisetron and granisetron in E. granulosus sensu stricto (s.s.) and assessed the expression of the calcineurin ( $\mathrm{CaN}$ ) and calmodulin (CaM) genes, both of which have been linked to cellular signaling activities and thus are potentially promising targets for the development of drugs.
\end{abstract}

Methods: Protoscoleces (PSC) of E. granulosus (s.s.) (genotype G1) obtained from sheep hepatic hydatid cysts were exposed to tropisetron and granisetron at concentrations of 50,150 and $250 \mu \mathrm{M}$ for various periods of time up to 10 days. Cyclosporine A (CSA) and albendazole sulfoxide were used for comparison. Changes in the morphology of PSC were investigated by light microscopy and scanning electron microscopy. Gene expression was assessed using realtime PCR at the mRNA level for E. granulosus calcineurin subunit A (Eg-CaN-A), calcineurin subunit B (Eg-CaN-B) and calmodulin (Eg-CaM) after a 24-h exposure at 50 and $250 \mu \mathrm{M}$, respectively.

Results: At 150 and $250 \mu \mathrm{M}$, tropisetron had the highest protoscolicidal effect, whereas CsA was most effective at $50 \mu \mathrm{M}$. Granisetron, however, was less effective than tropisetron at all three concentrations. Examination of morphological alterations revealed that the rate at which PSC were killed increased with increasing rate of PSC evagination, as observed in PSC exposed to tropisetron. Gene expression analysis revealed that tropisetron at $50 \mu \mathrm{M}$ significantly upregulated Eg-CaN-B and Eg-CaM expression while at $250 \mu \mathrm{M}$ it significantly downregulated both Eg-CaN-B and EgCaM expressions; in comparison, granisetron decreased the expression of all three genes at both concentrations.

Conclusions: Tropisetron exhibited a higher efficacy than granisetron against E. granulosus (s.s.) PSC, which is probably due to the different mechanisms of action of the two drugs. The concentration-dependent effect of tropisetron

\footnotetext{
*Correspondence: keiaeshr@tums.ac.ir; Dehpoura@tums.ac.ir

${ }^{1}$ Department of Medical Parasitology and Mycology, School of Public Health, Tehran University of Medical Sciences, Tehran, Iran

${ }^{5}$ Experimental Medicine Research Center, Tehran University of Medical Sciences, Tehran, Iran

Full list of author information is available at the end of the article
}

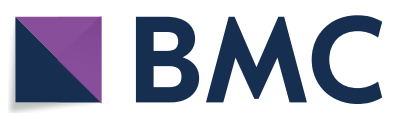

(c) The Author(s) 2021. This article is licensed under a Creative Commons Attribution 4.0 International License, which permits use, sharing, adaptation, distribution and reproduction in any medium or format, as long as you give appropriate credit to the original author(s) and the source, provide a link to the Creative Commons licence, and indicate if changes were made. The images or other third party material in this article are included in the article's Creative Commons licence, unless indicated otherwise in a credit line to the material. If material is not included in the article's Creative Commons licence and your intended use is not permitted by statutory regulation or exceeds the permitted use, you will need to obtain permission directly from the copyright holder. To view a copy of this licence, visit http://creativeco mmons.org/licenses/by/4.0/. The Creative Commons Public Domain Dedication waiver (http://creativecommons.org/publicdomain/ zero/1.0/) applies to the data made available in this article, unless otherwise stated in a credit line to the data. 
on calcineurin gene expression might reflect its dual functions, which should stimulate future research into its mechanism of action and evaluation of its potential therapeutical effect in the treatment of CE.

Graphic Abstract: Keywords: Tropisetron, Granisetron, Cyclosporine A, Albendazole sulfoxide, Echinococcus granulosus, Calcineurin, Calmodulin, In vitro

\section{Background}

Human cystic echinococcosis (CE) is a global zoonosis caused by the larval or metacestode stage of the dog tapeworm Echinococcus granulosus sensu lato (s.l.) [1]. Treatment of $\mathrm{CE}$ is often expensive and complicated, requiring extensive surgery and/or prolonged drug therapy [2]. There are four options for the treatment of CE: (i) percutaneous treatment of the hydatid cysts with the PAIR (puncture, aspiration, injection, re-aspiration) technique; (ii) surgery; (iii) anti-parasitic drug treatment; and (iv) the "watch and wait" approach [2]. The benzimidazole (BMZ) compounds albendazole and mebendazole have been the cornerstone of drug-based CE treatment [1]. These are typically administered to inoperable patients with liver or lung $C E$ and patients with multiple cysts in two or more organs, or peritoneal cysts [3]. Benzimidazoles are also used to prevent recurrence following surgery or PAIR [4]. However, long-term use of these compounds is linked to the development of adverse effects, including hepatotoxicity, severe leucopenia, thrombocytopenia and alopecia. Therefore, new and more efficient treatment options are urgently needed [5].

Drug repurposing is a useful strategy to accelerate drug development due to the associated lower costs, reduced risk of treatment failure and feasible marketing based on the availability of preclinical data. This strategy enables not only pharmaceutical companies but also public sector researchers to engage in drug discovery and development efforts [6]. Tropisetron and granisetron are selective receptor antagonists of serotonin 3 (5-hydroxytryptamine $\left.3\left[5-\mathrm{HT}_{3}\right]\right)$ that are widely used as effective, well-tolerated and safe agents to counteract chemotherapy-induced emesis [7]. However, tropisetron, but not granisetron, has been shown also to inhibit the phosphatase activity of calcineurin $(\mathrm{CaN})$, an enzyme that is pivotal in activating transcriptional factors responsible for immune/inflammatory axis regulation at both the transcriptional and protein levels and to target $\mathrm{CaN}$ in a receptor-independent fashion [8]. Moreover, it was found that tropisetron specifically inhibits both interleukin 2 (IL-2) gene transcription and IL-2 synthesis in stimulated $\mathrm{T}$ cells and inhibits early and late events in T-cell activation [9]. Nevertheless, it remains undetermined whether tropisetron directly inhibits $\mathrm{CaN}$ or whether it acts via $\mathrm{CaN}$-interacting molecules such as immunophilins [8]. The identification of tropisetron mechanisms other than the antagonism of $5-\mathrm{HT}_{3}$ receptors could form a basis for new drug development [8].

Calcineurin, known as protein phosphatase 2B (PP2B), is a $\mathrm{Ca}^{2+}$-calmodulin (CaM)-activated serine/threonine protein phosphatase involved in different signaling pathways. It is a heterodimeric protein consisting of the catalytic subunit $\mathrm{CaN} A(\mathrm{CaN}-\mathrm{A})$ and the $\mathrm{Ca}^{2+}$-binding subunit, CaN B (CaN-B) [10]. Calcineurin plays a key role in the coupling of local or global calcium signals, which in turn control immediate cellular responses and modify gene transcription [11]. The biological functions of $\mathrm{CaN}$ have been studied in several organisms, including parasitic helminths such as Schistosoma mansoni, Hymenolepis microstoma and $H$. diminuta, in which $\mathrm{CaN}$ is involved in ion homeostasis and regulation of exocytosis $[12,13]$. CaN has also been characterized in larval stages of E. granulosus (s.l.), and CaN-A has been immunolocalized in the cytoplasm of tegumental cells, suckers and excretory bladder of protoscoleces (PSC) [14].

The CaM gene is also expressed in the tegument tissue and parenchymal region of PSC $[15,16]$. In terms of evolution, $\mathrm{CaM}$ is one of the most ancient proteins in eukaryotes. The functions of CaM include $\mathrm{Ca}^{2+}$ binding and conversion of $\mathrm{Ca}^{2+}$ signals through downstream proteins to regulate various physiological processes, such as muscle contraction, metabolism and cell motility [17]. Calcineurin and $\mathrm{CaM}$ have been linked to the regulation of the life cycle, development and cellular signaling activities, thus being potentially promising targets for the development of drugs that block the invasion of parasites and limit their growth $[14,15]$.

With the aim to evaluate new compounds against $E$. granulosus sensu stricto (s.s.) PSC by means of drug repurposing, this study was designed to evaluate the effectiveness of two safe and clinically available drugs: tropisetron and granisetron. Tropisetron, which has a dual molecular signaling pathway [9], and granisetron, both of which are selective $5-\mathrm{HT}_{3}$ receptor antagonists [18], were used in vitro in comparison with the immunosuppressant drug cyclosporine A (CsA), which is a non-competitive inhibitor of $\mathrm{CaN}$ phosphatase activity [19]. CsA binds to cyclophilin proteins and prevents conformational changes in the $\mathrm{CaN}-\mathrm{A}$ subunit, which is an enzyme involved in T-cell activation [20]. The effects of CsA on E. granulosus (s.l.) PSC have already been reported [21], but the exact mechanism of action 
remains unknown. Albendazole sulfoxide (ABZSO), the protoscolicidal metabolite of albendazole [1], was also included in the evaluation as an already known effective compound currently used in CE treatment [22]. Moreover, changes in E. granulosus $\mathrm{CaN}(\mathrm{Eg}-\mathrm{CaN})$ and E. granulosus $\mathrm{CaM}$ (Eg-CaM) gene expression at the mRNA level were analyzed and the morphological changes in the PSC were evaluated using light and scanning electron microscopy (SEM).

\section{Methods}

\section{Collection of PSC}

Sheep unilocular hepatic hydatid cysts were provided by abattoirs from the Tehran Province, Iran, and immediately transferred to the Helminthology Laboratory at the School of Public Health, Tehran University of Medical Sciences. Under aseptic conditions, each hydatid cyst was cut open, and the solution containing PSC was aspirated by a syringe and then allowed to settle in a $50-\mathrm{ml}$ Falcon tube. After precipitation of the parasites, the supernatant was discarded and the PSC were washed three times with sterile phosphate-buffered saline (PBS) (pH 7.2). The viability of the PSC was assessed using an exclusion test [23] that consisted of observing PSC impermeability to $0.1 \%$ eosin solution using light microscopy. Red-stained PSC were considered to be dead, whereas colorless PSC were considered to be viable. The drug assessment tests involved numerous PSC with $>90 \%$ viability and belonging to E. granulosus (s.s.) G1 genotype. Genotype identification was performed on the samples of PSC retrieved from every appropriate pellet (with > 90\% viable PSC) and according to the procedure described below.

\section{Genotype determination of PSC}

Total genomic DNA of PSC was extracted using the High-Pure PCR Template Preparation Kit (Roche, Mannheim, Germany) according to the manufacturer's instructions. The cytochrome $c$ oxidase subunit $1(\operatorname{cox} 1)$ gene of the mitochondrial genome was amplified and sequenced to reveal the genotype of PSC isolated from the hydatid cysts. The PCR was carried out as described by Bowles et al. [24] using the primers JB3 ( $5^{\prime}$-TTT TTT GGG CAT CCT GAG GTT TAT-3') and JB4.5 (5'-TAA AGA AAG AAC ATA ATG AAA ATG-3'), and the PCR product was sequenced using primers JB3 and JB4.5 at Bioneer Corporation (Daejeon, South Korea). The obtained sequences (amplicon size: $366 \mathrm{bp}$ ) were assembled using Chromas v.2.6.4 (Technelysium Pty Ltd., Brisbane, Queensland, Australia) and compared with sequences previously deposited at the National Center for Biotechnology Information (NCBI) using the BLAST tool (http://www.ncbi.nlm.nih.gov/blast).

\section{Culture of E. granulosus (s.s.) PSC}

In vitro culture of the collected and washed PSC was as previously described [25]. Briefly, the PSC were transferred from the Falcon tube into filter-capped $75-\mathrm{cm}^{2}$ cell culture flasks containing culture medium [Dulbecco's Modified Eagle Medium (DMEM) containing glutamax, D-glucose (4.5 g/l), HEPES (15 mM), sodium pyruvate, $\mathrm{NaHCO}_{3}$ (Gibco, New York, NY, USA) and $1 \%$ penicillin-streptomycin (Biosera, Nuaille, France), with $0.5 \mu \mathrm{g}$ amphotericin B solution (Caisson Laboratories Inc., North Logan, UT, USA)], supplemented with $10 \%$ fetal calf serum (Biosera, Nuaille, France). Prior to initiation of the in vitro drug assay, the culture medium containing the PSC was maintained in an incubator at $37{ }^{\circ} \mathrm{C}$ and $5 \% \mathrm{CO}_{2}$ for $24 \mathrm{~h}$ to ensure that the medium was not contaminated with fungal or bacterial infections.

\section{In vitro drug assays}

With regard to the drug mixture preparations, tropisetron monohydrochloride (CAS no.: 105,826-92-4, Product no.: T104; Sigma-Aldrich, St. Louis, MO, USA) and granisetron hydrochloride (CAS no.: 107,007-998, Product no.: G3796; Sigma-Aldrich China, Shanghai, China), which are soluble in water, were diluted directly in the culture medium. However, CsA (CAS no.: 5986513-3, Product no.: 30024, Sigma-Aldrich USA) and ricobendazole (ABZSO) (CAS no: 54029-12-8, Product no: 19953; Sigma-Aldrich China) were first dissolved in dimethyl sulfoxide (DMSO)(CAS no.: D8779, Product no: 67-68-5, Sigma-Aldrich USA) at an amount of $<0.3 \%$, which has no deleterious effect on the parasite [26], and then diluted in the culture medium. Treatment of the PSC was initiated 1 day after initiation of in vitro culture. For all drugs, three final concentrations were prepared:50, 150 and $250 \mu \mathrm{M}$. Additionally, two cell culture flasks containing non-treated PSC were used as control cultures; one with culture medium only, and the other supplemented with DMSO. All treated PSC and the two controls were dispersed in the flasks at approximately equal numbers $(n=25,000)$, with medium change on day 5 of the initiation of the drug assessment. Protoscolex viability assessment following initiation of drug exposure was performed at 1 -h inspections during the first $12 \mathrm{~h}$ and then at 24-h intervals up to the tenth day. The viability of the PSC was evaluated after gentle mixing of the solutions using an eosin $0.1 \%$ exclusion test [23] with microscopic observation of change in the color of the PSC. Viability was calculated as the proportion of viable PSC among the total number of PSC in ten microscopic fields at $\times 10$ magnification. Each run of drugs tests was carried out in three replicates per treatment condition 
and repeated three times. After $24 \mathrm{~h}$ of drug exposure, some samples of treated PSC were harvested from the preparations containing $250 \mu \mathrm{M}$ of the respective drug for SEM, and from those containing 50 and $250 \mu \mathrm{M}$ for RNA extraction and comparison with the two controls.

\section{Scanning electron microscopy}

Some specimens of PSC treated with tropisetron, granisetron, CsA and ABZSO at $250 \mu \mathrm{M}$ for $24 \mathrm{~h}$, as well as controls (medium control and DMSO control) were fixed with $2.5 \%$ glutaraldehyde in sodium cacodylate buffer for $24 \mathrm{~h}$ at $4{ }^{\circ} \mathrm{C}$. After several rounds of washing in cacodylate buffer, samples were first fixed in $2 \%$ OsO4 in cacodylate buffer, then extensively washed in distilled water, dehydrated by sequential incubations in increasing concentrations of ethanol (50-100\%), immersed in hexamethyldisilazane and air-dried under a fume hood [27]. The samples were then sputter-coated with gold (thickness: $100 \AA$ ) and observed with a scanning electron microscope (field emission-SEM; Hitachi model S-4160; Hitachi Ltd., Tokyo, Japan) operating at $20 \mathrm{kV}$. Finally, for each sample, four regions were visualized: (i) complete protoscolex ( $\times 500$ magnification); (ii) sucker and rostellum ( $\times 1100$ magnification); (iii) microtriches $(\times 30,000$ magnification); and (iv) soma region ( $\times 30,000$ magnification).

\section{Molecular analysis}

\section{Gene identification and primer design}

Calcineurin genes of subunit A (Eg-CaN-A) and B (Eg$\mathrm{CaN}-\mathrm{B})$ and $\mathrm{Eg}-\mathrm{CaM}$ were selected as the main genes for assessment, and glyceraldehyde 3-phosphate dehydrogenase (GAPDH) was chosen as reference gene. The sequences of these genes were obtained from two references [28, 29] available in the NCBI (accession no.: Xm_024493804, Xm_024491779, Xm_024490475 and Xm_024494574) or GENDB (accession no.: EgrG_000601200, EgrG_000454300, EgrG_000491400 and EgrG_0002546000) databases. Primers (Table 1) were designed using Allele ID (Premier Biosoft, Palo Alto, CA, USA) and MEGA v.7 and Gene Runner v.5.0.59 software and synthesized by Metabion International AG (Planegg, Germany).

\section{Total RNA extraction and $C D N A$ synthesis}

Some PSC exposed to different drugs at 50 and $250 \mu \mathrm{M}$ for $24 \mathrm{~h}$, as well as controls (medium control and DMSO control) were placed in liquid nitrogen overnight and then physically shattered using syringes and needles and examined under an optical microscope to ensure that their walls were crushed. RNA was then extracted using the RNeasy Mini Kit (Qiagen, Hilden, Germany), according to the manufacturer's instructions. RNA concentration was measured with a NanoDrop spectrophotometer (Thermo Fisher Scientific, Waltham, MA, USA). All concentrations were $<100 \mathrm{ng} / \mathrm{ml}$, and absorption ratios at 280/260 nm were between 1.7 and 2.2. cDNA was then synthesized using the Quanti Nova Reverse Transcription Kit (Qiagen), according to the manufacturer's instructions, and stored at $-20{ }^{\circ} \mathrm{C}$ until processed in real-time PCR assays.

\section{Real-time PCR analyses}

For the real-time PCR analyses, $1 \mu$ l of diluted (1:2) cDNA was used in a final reaction volume of $20 \mu \mathrm{l}$ containing $10 \mu \mathrm{l}$ of SYBR Premix Ex Taq II $(2 \times), 0.4$ ROX Reference Dye (Takara, Tokyo, Japan), $400 \mathrm{nM}$ of each of the forward and the reverse primers, using the Step One Plus Real-Time PCR System (Applied Biosystems, Foster City, CA, USA). The reaction conditions included an initial activation step at $95{ }^{\circ} \mathrm{C} / 2 \mathrm{~min}$; denaturation at 95 ${ }^{\circ} \mathrm{C} / 15 \mathrm{~s}$, annealing at $60{ }^{\circ} \mathrm{C} / 1 \mathrm{~min}$, extension at $72{ }^{\circ} \mathrm{C} / 30$ $\mathrm{s}$ for 45 cycles. The point of quantification was adjusted according to the melting curves of the primers, and LinRegPCR v.2017.1 software (Ruijter et al., Amsterdam, the Netherlands; https://www.gene-quantification.de/LinRe gPCR_help_manual_v11.0.pdf) was used to obtain data on PCR amplification efficiency.

\section{Statistical analysis}

Data on changes in gene expression were analyzed using the REST 2009 software. Data on protoscolex

Table 1 Genes and corresponding primers for the gene expression analysis of Echinococcus granulosus (s.s.) protoscoleces exposed to the various drugs

\begin{tabular}{llllc}
\hline Gene & Forward primer $\left(5^{\prime}-3^{\prime}\right)$ & Reverse primer (5'-3') & $\begin{array}{l}\text { Amplicon length } \\
(\mathrm{bp})\end{array}$ & PCR efficiency \\
\hline Calcineurin A & GGACGACATTAGGCGGATTG & GCTGAGTAACTGAAGAAGTAGGAG & 165 & 1.95 \\
Calcineurin B & ATACGGATGGGATGGCGA & CATCTTAGAACCTGGAAAAGCTC & 167 & 1.93 \\
Calmodulin & ATCACCACCAAGGAATTAGGG & CGTCCCATTACCGTCTGC & 108 & 1.91 \\
GAPDH & TTCCACCACCTGCTCCTC & CCAAACTCATTATCGTACCAAGC & 96 & $1.90-1.93$ \\
\hline
\end{tabular}

GAPDH Glyceraldehyde 3-phosphate dehydrogenase 
viability and gene expression levels were presented as means \pm standard deviations (SD) and illustrated using GraphPad Prism software (version 8.3.0; GraphPad Software, San Diego, CA, USA). Statistical analyses between groups used one-way analysis of variance (ANOVA) for gene expression analysis, and two-way ANOVA for viability evaluation with Dunnett post hoc tests. A $P$ value of $\leq 0.05$ was considered to be statistically significant.

\section{Results}

\section{Sequence analysis}

Protoscoleces processed for the investigations described in the following sections showed $100 \%$ identity with the E. granulosus (s.s.) G1 genotype (NCBI GenBank sequence HM563011) [30].

\section{Effect of drug exposure on E. granulosus (s.s.) PSC}

Based on the results of the viability tests in both of the controls, the viability rate of PSC was $>95 \%$ after $240 \mathrm{~h}$ (10 days) of cultivation. Data on drug efficiency at each concentration are provided below.

\section{Concentration of $250 \mu \mathrm{M}$}

The highest protoscolicidal effect at this concentration was observed for tropisetron. After $24 \mathrm{~h}$ of exposure to $250 \mu \mathrm{M}$ tropisetron, $80 \%$ of the PSC were deemed nonviable (Fig. 1a). Protoscolex degeneration initiated from the scolex region and then spread to the soma region.
Most of the PSC were evaginated (>90\% after $5 \mathrm{~h}$ ) (Fig. 2Aa). Numerous blebs were observed on the tegument of the PSC, and shedding of the hooks was also noted (Fig. 2Ba).

More than $90 \%$ of the PSC exposed to granisetron exhibited evagination after $72 \mathrm{~h}$. The protoscolicidal effect of granisetron was $92 \%$ after $168 \mathrm{~h}$ of exposure (Fig. 1a). Blebs were noted in the soma and in the scolex region (Fig. 2Bb). In addition, a large amount of the PSC had developed into the vesicular, evaginated form after $96 \mathrm{~h}$ (Fig. 2Bb).

With regard to CsA, a protoscolicidal effect was observed after $24 \mathrm{~h}$ of exposure. PSC consisted of both invaginated and evaginated forms (Fig. 2Ad), with $>90 \%$ of PSC having evaginated after $48 \mathrm{~h}$. The tegument of the PSC contracted at the anterior soma region after $120 \mathrm{~h}$ of exposure, and blebs were observed to be bulging all over the tegument (Fig. 2Bc). More than $90 \%$ of the parasites were dead after $144 \mathrm{~h}$.

Most of the ABZSO-treated PSC (>90\%) remained invaginated after $24 \mathrm{~h}$ (Fig. 2Ae). ABZSO-mediated alterations in the PSC were microscopically visible after 96 $\mathrm{h}$, and after $240 \mathrm{~h}$, the level of evagination had reached approximately $30 \%$ (Fig. 1a). Protoscoleces were permeable to eosin at the site of the scolex and soma region, and the presence of knob-like projections was observed at the soma region (Fig. 2Bd).

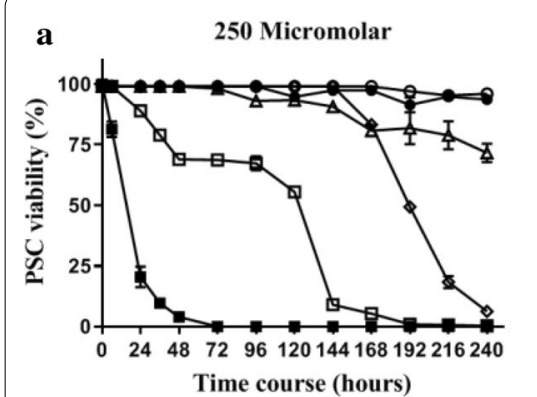

c $\quad 50$ Micromolar

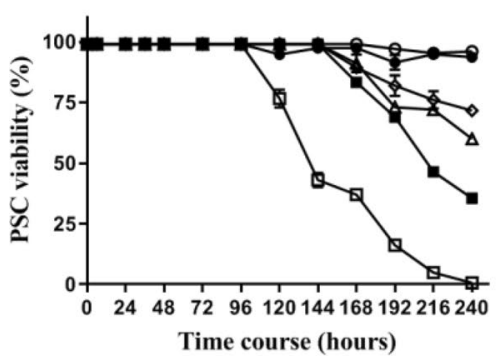

- Tropisetron

- Granisetron

廿 Cyclosporine A

— Albendazole sulfoxide

- Medium control

$\rightarrow$ DMSO control

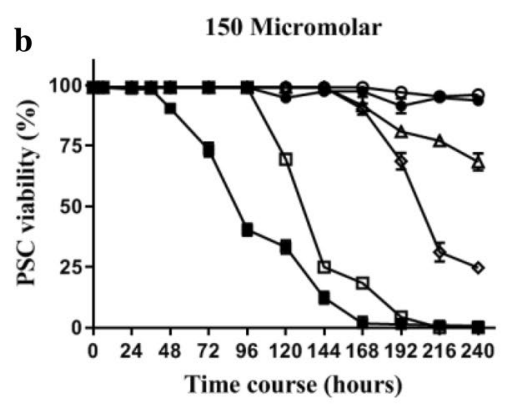

- Tropisetron

* Granisetron

廿 Cyclosporine A

$\triangle$ Albendazole sulfoxide

- Medium control

$\rightarrow$ DMSO control
* Tropisetron

$\leftarrow$ Granisetron

廿 Cyclosporine A

$\triangle$ Albendazole sulfoxide

- Medium control

$\rightarrow$ DMSO control

Fig. 1 Trends in viability of Echinococcus granulosus (s.s.) protoscoleces (PSC) exposed to tropisetron, granisetron, cyclosporine A (CSA) and albendazole sulfoxide (ABZSO), for various exposure time courses ranging from $24 \mathrm{~h}$ to $240 \mathrm{~h}$ (10 days), at three concentrations: $250 \mu \mathrm{M}$ (a), $150 \mu \mathrm{M}$ (b) and $50 \mu \mathrm{M}$ (c). DMSO Dimethyl sulfoxide 

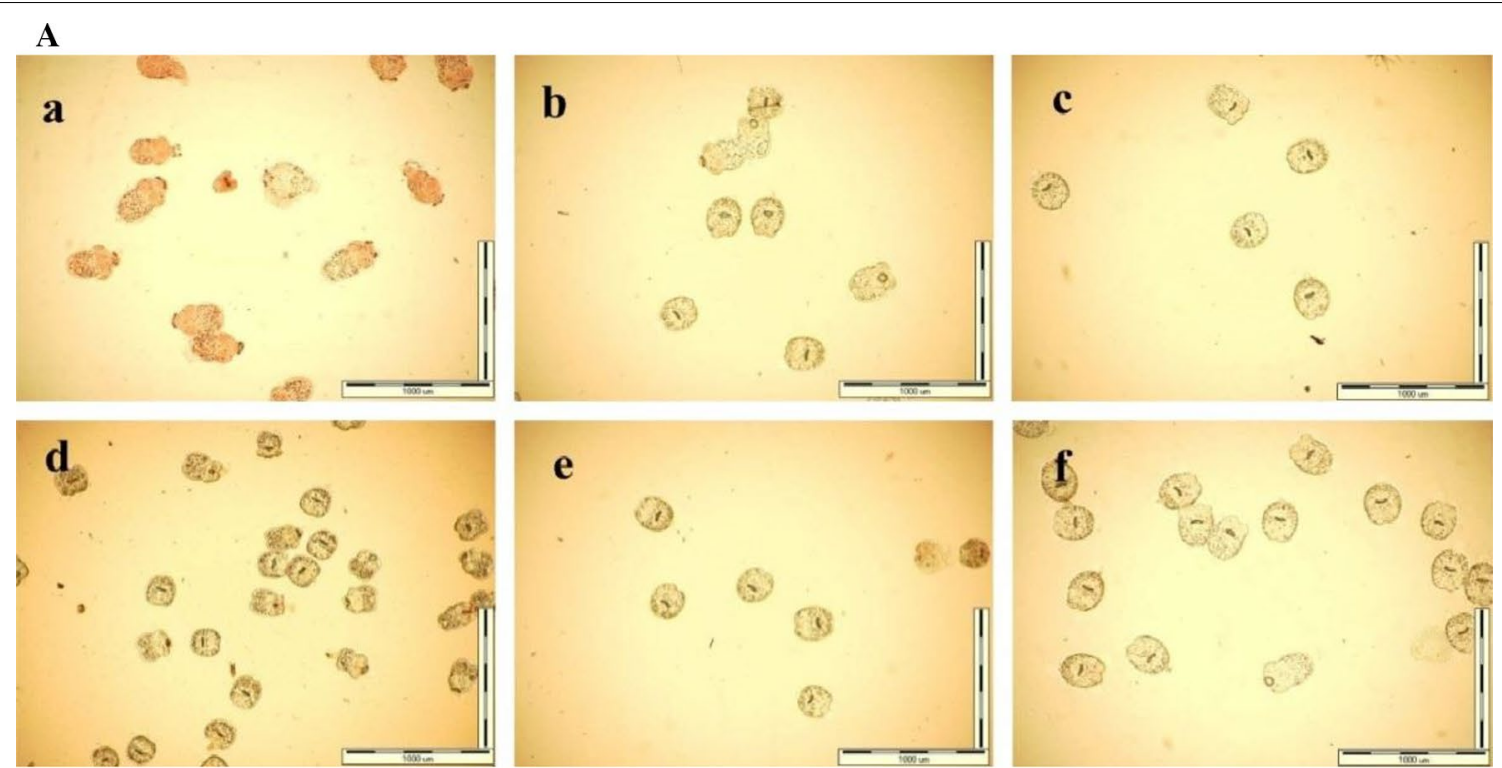

B
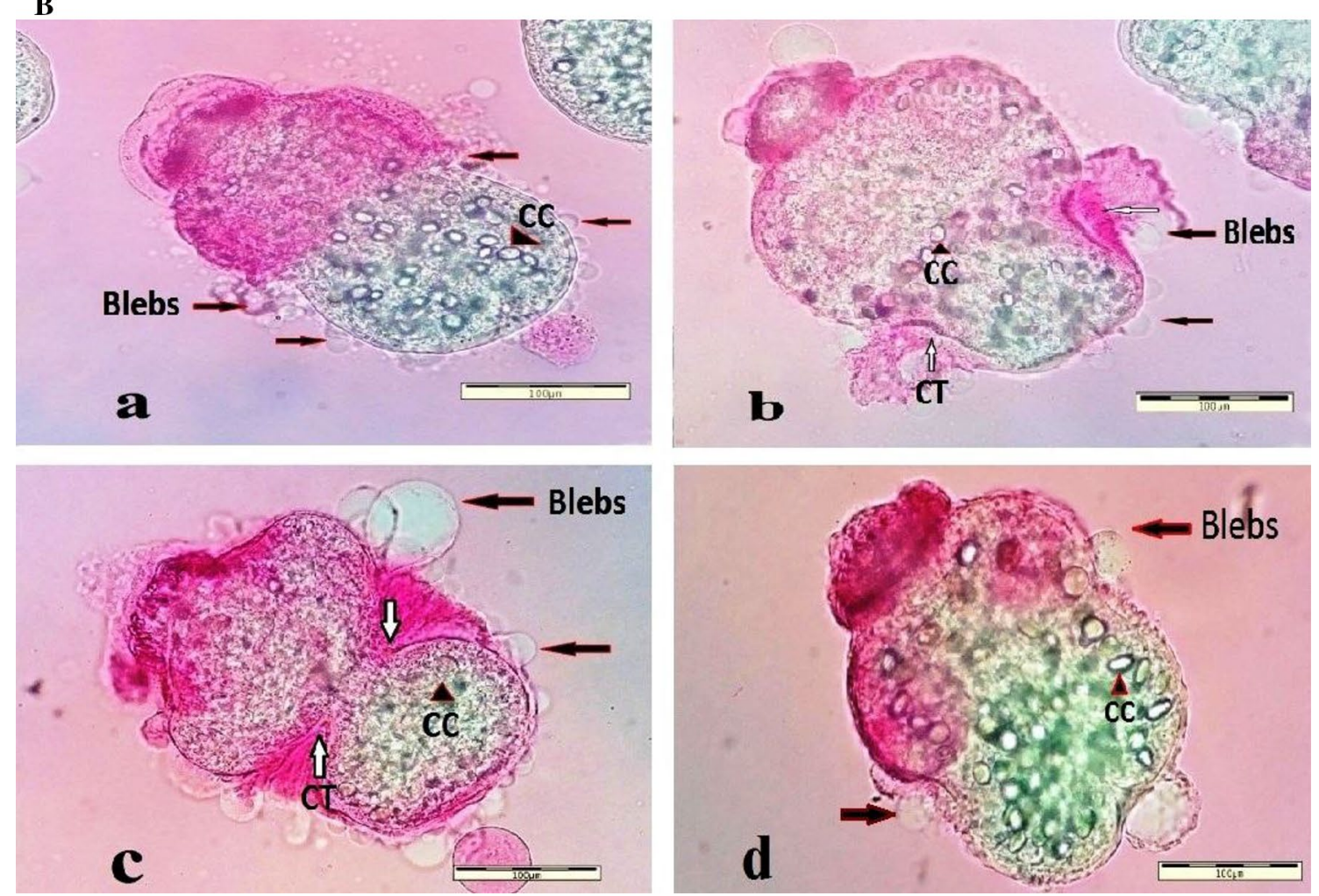

Fig. 2 Optical microscope photographs of E. granulosus (s.s.) protoscoleces (PSC) exposed to different drugs and the non-exposed controls. A PSC after a 24-h exposure to $250 \mu \mathrm{M}$ of tropisetron (a), granisetron (b), medium control (c), CsA (d), ABZSO (e), DMSO control (f); (magnification $\times 40)$. B PSC exposed to $250 \mu \mathrm{M}$ of tropisetron after $24 \mathrm{~h}(\mathbf{a})$, granisetron after $175 \mathrm{~h}(\mathbf{b}), \mathrm{CsA}$ after $120 \mathrm{~h}(\mathbf{c})$, ABZSO after $140 \mathrm{~h}$ (d); (magnification $\times 400)$. The presence of blebs in the tegument of the PSC $(\mathbf{a}, \mathbf{b}, \mathbf{c}, \mathbf{d})$, contraction of the tegument (CT) at the soma region ( $\mathbf{b}, \mathbf{c})$, and calcareous corpuscles (CC) in parenchyma of the PSC $(\mathbf{a}, \mathbf{b}, \mathbf{c}, \mathbf{d})$ are visualized 


\section{Concentrations of 150 and $50 \mu M$}

At concentrations of 150 and $50 \mu \mathrm{M}$, the time taken to trigger 90\% evagination of the PSC was 48 and $96 \mathrm{~h}$ for tropisetron, 96 and $144 \mathrm{~h}$ for granisetron and 72 and $72 \mathrm{~h}$ for CsA, respectively. The evagination of PSC exposed to ABZSO was $<40 \%$ after $240 \mathrm{~h}$.

Tropisetron began to exhibit protoscolicidal effects at $150 \mu \mathrm{M}$ after $48 \mathrm{~h}$, leading to death of $100 \%$ of PSC after $168 \mathrm{~h}$. Exposure to CsA led to $100 \%$ mortality after $192 \mathrm{~h}$, while exposure to granisetron and ABZSO led to 75 and $30 \%$ mortality, respectively, after 240 h (Fig. 1b). After incubation for $240 \mathrm{~h}$ with $50 \mu \mathrm{M}$ of the studied drug, different mortality rates were observed:100\% for CsA, $65 \%$ for tropisetron, $40 \%$ for ABZSO and $30 \%$ for granisetron (Fig. 1c).

\section{Scanning electron microscopy}

The PSC exposed to tropisetron exhibited a number of alterations, including rostellar disorganization, loss of hooks (Fig. 3Ab), destruction or shedding of microtriches (Fig. 3Ac) and contraction and marked tegumental change in the soma region (Fig. 3Ad). In those PSC exposed to granisetron, the tegument of the scolex and soma region remained unchanged (Fig. 3Bb), with regularity of the microtriches (Fig. 3Bc) and smoothness of the soma region (Fig. 3Bd). The PSC exposed to CsA showed marked alteration of the microtriches (Fig. 3Dc) and formation of tegumental vesicles in the soma region (Fig. 3Dd). In ABZSO-treated PSC, the microtriches remained stable (Fig. 3Ec); however, compared with those of the DMSO control group, minor alterations in the soma region were noted (Fig. 3Ed). In the PSC of the medium control (Fig. 3C) and the DMSO control (Fig. 3F), no significant alterations were visible in the tegument of the scolex or in the soma region was.

\section{Analysis of calcineurin A, calcineurin B, and calmodulin gene expression}

In the PSC exposed to tropisetron, the expression levels of both the $\mathrm{Eg}-\mathrm{CaN}-\mathrm{B}$ and $\mathrm{Eg}-\mathrm{CaM}$ genes were upregulated at $50 \mu \mathrm{M}$ tropisetron and downregulated at $250 \mu \mathrm{M}$ (Fig. 4). However, the expression of all three genes was downregulated at both of these concentrations in the PSC exposed to granisetron, in contrast to PSC exposed to ABZSO, which exhibited upregulation of all three genes at both concentrations. As for CsA, apart from the downregulation of $\mathrm{Eg}$-CaM at $250 \mu \mathrm{M}$, only upregulations were noted. $P$ values applicable to differences in gene expression changes are provided in Fig. 4.

\section{Discussion}

In this study, we showed that both tropisetron and granisetron (5- $\mathrm{HT}_{3}$ antagonists) have dose-dependent protoscolicidal effects, but that this effectiveness is much stronger for tropisetron. The lack of an inhibitory effect of ondansetron, a selective $5-\mathrm{HT}_{3}$ receptor antagonist, on Echinococcus motor activity induced by 5-HT or serotonin suggested that perhaps additional 5-HT receptors in the parasite are involved [31]. In the same way, it is assumed that the current results on the significant difference between the protoscolicidal effect of granisetron and tropisetron is most probably due to the dual molecular signaling pathway [9] of tropisetron and its function through a pathway other than $5-\mathrm{HT}_{3}$. Therefore, further studies are necessary to determine the exact mechanism of the robust protoscolicidal effect of tropisetron.

With regard to CsA, its in vitro protoscolicidal effect has already been confirmed [21,32]. The results of our study also indicated that it had a dose-dependent protoscolicidal effect at the same dose previously evaluated, although earlier studies reported a stronger protoscolicidal effect than observed in our study [32,33]. This difference is assumed to be related to protoscolex activation prior to the drug exposure in the previous studies [32, 33], which was not performed in our study.

Albendazole is a drug whose protoscolicidal effects are well known, and it is currently used for CE chemotherapy [22]. Consistent with previous studies [34], our study also demonstrated the protoscolicidal effects of ABZSO, although it was less effective than tropisetron at all three administrated concentrations. It has been reported that praziquantel (PZQ) has a stronger in vitro protoscolicidal effect than ABZSO [35], but the in vivo use of PZQ was found to be less successful than albendazole [36], leading to the postulation that prior damage to the cyst wall by albendazole might facilitate the penetration and action of PZQ [37]. In the same way, the in vivo optimum duration and benefits of tropisetron as monotherapy and in combination with ABZSO and with PZQ in the treatment of $C E$ should be determined in future studies.

One of the most conspicuous morphological changes observed in the drug-exposed PSC in our study was their evagination. The examination of morphological alterations in the parasites during exposure to the three different concentrations of the four study drugs over various periods of time indicated that the more rapid the evagination of PSC, as observed in those exposed to tropisetron, the faster their death. In contrast, continued invagination was associated with longer parasite viability. In one study involving in vitro exposure to CsA, invaginated PSC exhibited longer survival than evaginated ones that are highly motile and possibly take up and metabolize CsA at a faster rate than the relatively invaginated PSC [32]. Since one of the functions of the microtriches is nutrient absorption [38], drugs that rapidly trigger evagination may have a relatively stronger effect. 


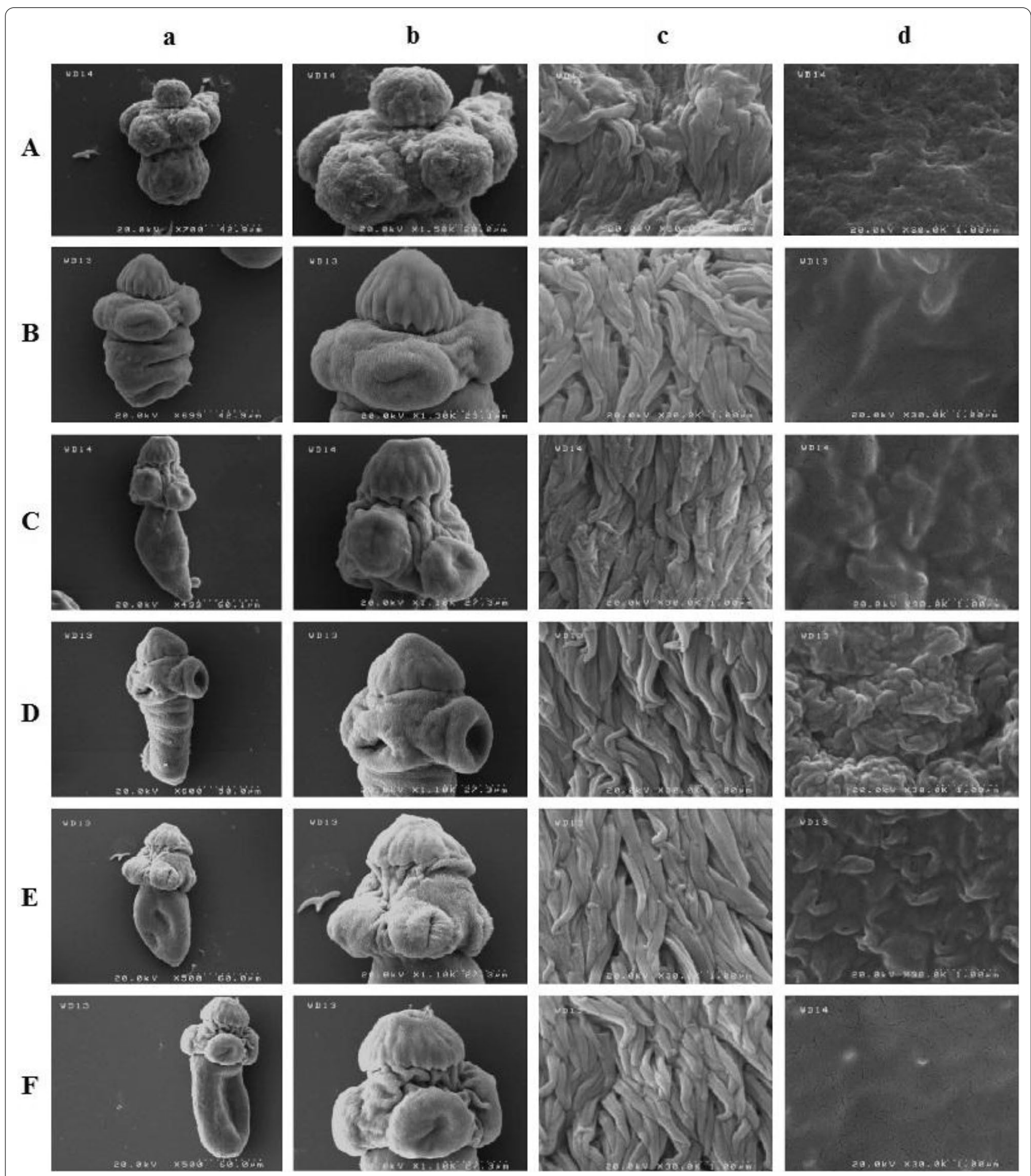

Fig. 3 Scanning electron microscopy images of E. granulosus (s.s.) protoscoleces exposed for $24 \mathrm{~h}$ to $250 \mu \mathrm{M}$ of the different drugs, including A tropisetron, $\mathbf{B}$ granisetron, $\mathbf{C}$ medium control, D CSA, E ABZSO and $\mathbf{F}$ DMSO control. a Complete protoscolex (magnification $\times 500$ ), $\mathbf{b}$ sucker (magnification $\times 1100$ ), $\mathbf{c}$ microtriches (magnification $\times 30,000$ ) and $\mathbf{d}$ soma region (magnification $\times 30,000$ ) 

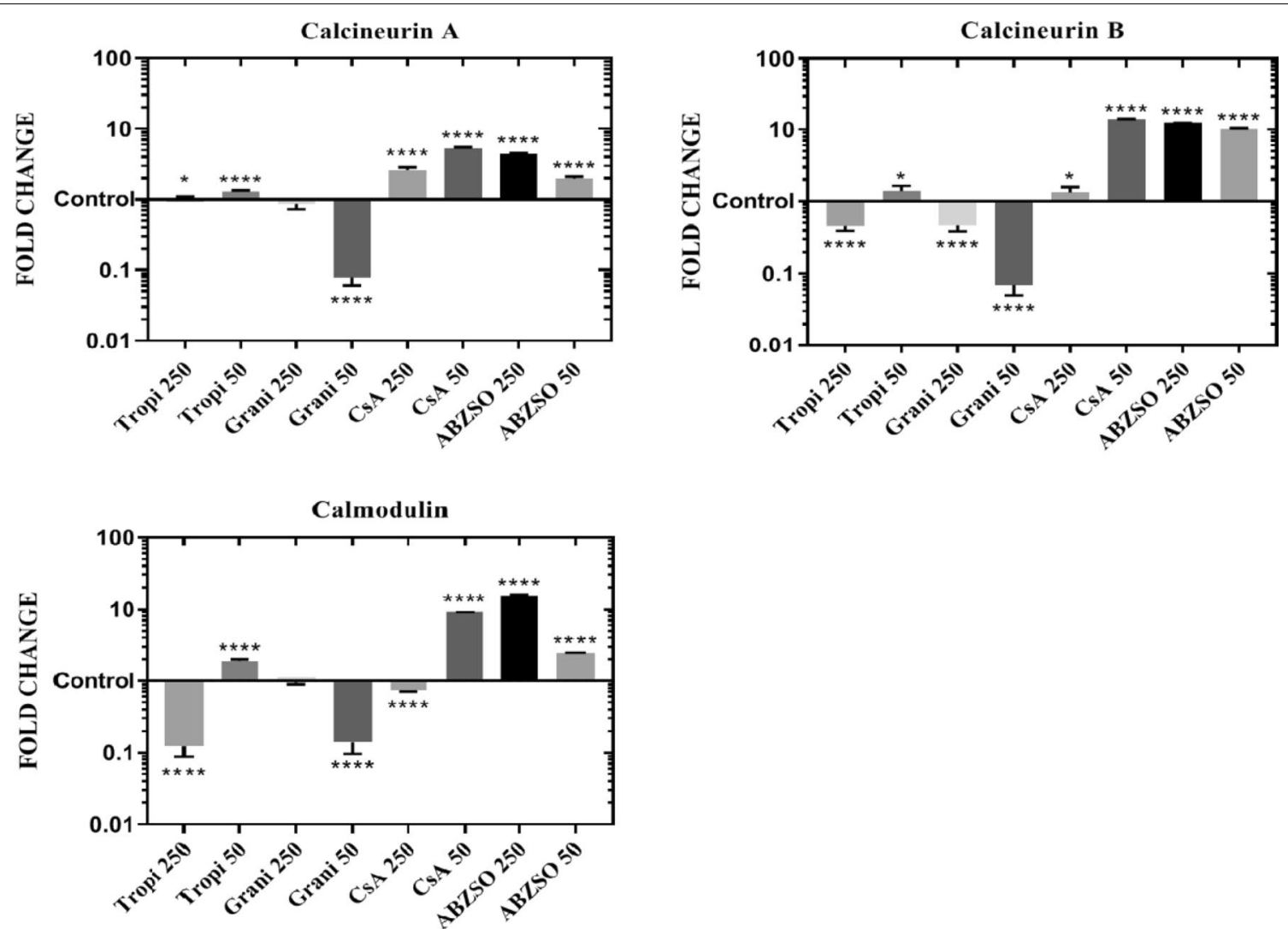

Fig. 4 Gene expression analysis of E. granulosus (s.s.) PSC exposed to two concentrations (50 and $250 \mu \mathrm{M}$ ) of the different drugs in comparison with the control. The evaluated genes were calcineurin A, calcineurin B and calmodulin. The vertical axis of the charts represents the levels of mRNA expression (fold change: log 10) in the exposed PSC and in the control group (fold change: 1). Fold change was calculated using REST 2009. The horizontal bars represent the mean \pm standard deviation of three repetitions of triplicate experiments. The $2^{-\triangle \triangle C T}$ was the method of analysis. Asterisks indicate statistically significant differences from the control at ${ }^{*} P<0.05$ and ${ }^{* * *} P<0.0001$, Tropi Tropisetron, Grani granisetron, CSA cyclosporine A, ABZSO Albendazole sulfoxide

Another morphological change observed in the treated PSC was the presence of blebs at the tegument surface. We noted the formation of protoscolex blebs in various shapes and sizes, which developed simultaneously with other alterations. The development of blebs in the forms of small blebs (blister) or ballooning blebs in PSC exposed to PZQ has also been reported [39]. Bleb formation is assumed to reflect "stress responses" brought about in PSC by any harmful condition [34]. It has also been suggested that the presence of blebs might reflect a membrane repair mechanism in response to druginduced damage or host antibody attacks [40]. Considering the variations in the size and shape of the blebs, it is possible that their development might rely on different mechanisms, but this hypothesis calls for further research.

SEM-based ultrastructural studies of PSC exposed for $24 \mathrm{~h}$ to $250 \mu \mathrm{M}$ concentrations of the drugs revealed that the PSC incubated with granisetron failed to display visible changes in the tegument of the scolex and in the soma region. ABZSO induced slight alterations on the tegument of the soma region only, without visible changes in the microtriches. In the same way, PSC exposed to CsA revealed marked alterations of microtriches on the scolex region together with the formation of tegumental vesicles in the soma region. In contrast, tropisetron triggered pronounced alterations in the tegument of both the scolex and the soma region. In an earlier SEM-based ultrastructural study [34], exposure of PSC to ABZSO at $10 \mu \mathrm{g} / \mathrm{ml}$ resulted in pronounced bleb formation on the tegument of the soma region and the loss of hooks and shedding of microtriches in the scolex region; it should be emphasized, however, that such alterations were noted by the authors only after an incubation period of 24 days. Moreover, in another SEM study [41], the protoscoleces incubated ex vivo with $10 \mu \mathrm{g} / \mathrm{ml}$ of flubendazole for 6 days exhibited contraction and tegumental alterations of the soma region, while those incubated with nitazoxanide at $10 \mu \mathrm{g} / \mathrm{ml}$ for 3 days exhibited shedding of microtriches in the scolex region in addition to contraction of the soma 
region with marked alterations of the tegument. These results lead to the suggestion that the actions of the various chemotherapy agents are time- and dose-dependent; those agents that induce changes in the scolex, such as shedding of the microtriches, apparently have stronger protoscolicidal effects. The results of the present study illustrating the rapid and pronounced tegumental alteration of the PSC by tropisetron is an important new finding, which should stimulate further assessments of the protoscolicidal effectiveness of this compound.

The activity of calcineurin is affected by changes in intracellular $\mathrm{Ca}^{2+}[10]$. This enzyme, in contrast to the many $\mathrm{Ca}^{2+}$-dependent kinases, is the only known protein phosphatase under the control of this cation and CaM [14]. A study on calcineurin expression in larval stages of E. granulosus (s.l.) also showed that Eg-CaN-B transcripts were downregulated in response to low intracellular $\mathrm{Ca}^{2+}$ levels; however, no change was found in the transcriptional level of Eg-CaN-A [14].

In the present study, gene expression was investigated for $\mathrm{Eg}-\mathrm{CaN}-\mathrm{A}, \mathrm{Eg}-\mathrm{CaN}-\mathrm{B}$ and $\mathrm{Eg}-\mathrm{CaM}$ after a 24-h exposure to granisetron, CsA, tropisetron and ABZSO, respectively, at concentrations of 50 and $250 \mu \mathrm{M}$. The results can be summarized as follows: (i) granisetron at both concentrations decreased the expression of EgCaN-B. As serotonin can increase intracellular calcium through 5-HT receptor activation [42], it is supposed that granisetron may act as a serotonin receptor antagonist rather than a $5-\mathrm{HT}_{3}$ receptor, and that when intracellular calcium levels are not increased, a reduction in CaN-B activity and $\mathrm{CaN}-\mathrm{B}$ gene downregulation is observed. In our study, CsA, in contrast to granisetron, increased Eg-CaN-B expression at both 50 and $250 \mu \mathrm{M}$. This drug increases intracellular calcium through inositol trisphosphate $\left(\mathrm{InsP}_{3}\right)$-dependent $\mathrm{Ca}^{2+}$ release, and calcineurin provides a negative feedback on $\mathrm{InsP}_{3} / \mathrm{Ca}^{2+}$ signaling in blowfly salivary glands [43]. Therefore, we postulate that in the current study, CsA probably increased intracellular calcium by inhibiting this enzyme, leading to an increase in Eg-CaN-B gene expression. Tropisetron exhibited contrasting effects on Eg-CaN-B gene expression at both 50 and $250 \mu \mathrm{M}$. Unlike granisetron and CsA, tropisetron triggered decreased Eg-CaN-B expression in PSC exposed to $250 \mu \mathrm{M}$, but increased gene expression when exposed to $50 \mu \mathrm{M}$. However, the extent of gene expression decrease and increase was more limited than that of corresponding concentrations of granisetron and CsA, respectively. We assume that this dual effect of tropisetron might reflect its function either as a 5-HT antagonist, which does not increase intracellular calcium, or as an inhibitor of the calcineurin phosphatase enzyme, which increases intracellular calcium levels. However, further studies are required to enable more precise speculations on this interesting finding and the exact mechanism of tropisetron.

Exposure to 50 and $250 \mu \mathrm{M}$ ABZSO resulted in an increased expression of the Eg-CaN-B gene. Since the calcineurin phosphatase enzyme is involved in tubulin polymerization [44] and albendazole inhibits betatubulin polymerization [45], it is likely that levels of phosphorylated tubulin dimers, as substrates of the CaN enzyme, are increased by the effect of ABZSO via inhibition of tubulin polymerization, which thereby results in $\mathrm{CaN}$ enzyme consumption and subsequent increased $\mathrm{Eg}-\mathrm{CaN}-\mathrm{B}$ gene expression.

The most important limitation of the present study was the lack of in vivo experiments to verify whether the drugs can pass through CE barriers. We did not establish an infection model for drug response monitoring. In line with the strategy of drug repurposing, the main strength of the study was the evaluation and documentation of the in vitro efficacy of tropisetron. This finding paves the way for evaluation of its application as a novel protoscolicidal agent during CE surgery and PAIR approaches informed by the results of future in vivo research.

\section{Conclusion}

To summarize, among the four drugs we tested in vitro on PSC of E. granulosus (s.s.), tropisetron had the most potent effects, leading to evagination of PSC more rapidly than the other administered drugs. In line with the urgent need for introducing alternative chemotherapy options for CE, this important outcome should stimulate further in vitro studies on the mechanism of actions and in vivo evaluation of tropisetron effectiveness. Since this compound is currently considered to be a safe drug in clinics, its usefulness as a protoscolicidal agent in CE surgery and PAIR approaches should be evaluated. Moreover, further studies on the potential therapeutical effects of tropisetron on CE in experimentally infected laboratory animals as well as in naturally infected ruminants are recommended.

\section{Abbreviations \\ ABZSO: Albendazole sulfoxide; BMZ: Benzimidazole; CaM: Calmodulin; CaN: Calcineurin; CE: Cystic echinococcosis; CSA: Cyclosporine A; DMSO: Dime- thyl sulfoxide; GAPDH: Glyceraldehyde 3-phosphate dehydrogenase; $5-\mathrm{HT}_{3}$ : 5-Hydroxytryptamine (serotonin) 3; PAIR: Puncture, aspiration, injection of the protoscolicidal agent, re-aspiration; PSC: Protoscoleces; SEM: Scanning electron microscopy.}

\section{Acknowledgements}

We would like to thank all people who contributed to the study, especially Dr. Saeedeh Shojaee and Mrs. Mahboobeh Salimi from the Department of Medical Parasitology and Mycology, School of Public Health, and Miss Nastaran Rahimi from the Department of Pharmacology, School of Medicine, Tehran University of Medical Sciences for their kind assistance. 


\section{Authors' contributions}

MRS, EBK and ARD designed and coordinated the study. MRS performed the experiments with technical guidance of FZ on viability assessments, MN on gene selection and primers design and EM and SN on the real-time PCR assay. FZ, MFH and MN contributed to the data analysis. MRS drafted the manuscript, and EBK and ARD revised and finalized it. All authors read and approved the final manuscript.

\section{Funding}

This study was part of the PhD thesis developed by the first author (MRS) in the Department of Medical Parasitology and Mycology, School of Public Health, Tehran University of Medical Sciences, Tehran, Iran. The study was approved and financially supported by the Deputy of Research, Tehran University of Medical Sciences (Grant No. 96-04-27-36315).

\section{Availability of data and materials}

The relevant information has been included in the manuscript. The datasets used and/or analyzed during the current study are available from the corresponding author on reasonable request.

\section{Declarations}

Ethics approval and consent to participate

The protocol was approved by the Ethics Committee of Tehran University of Medical Sciences (Protocol number: IR.TUMS.SPH.REC.1396.3645).

\section{Consent for publication}

Not applicable.

\section{Competing interests}

The authors declare that they have no competing interests.

\section{Author details}

1 Department of Medical Parasitology and Mycology, School of Public Health, Tehran University of Medical Sciences, Tehran, Iran. ${ }^{2}$ Cell-Based Therapies Research Center, Digestive Disease Research Institute, Tehran University of Medical Sciences, Tehran, Iran. ${ }^{3}$ Department of Molecular Medicine, School of Advanced Technologies in Medicine, Tehran University of Medical Sciences, Tehran, Iran. ${ }^{4}$ Research Center for Hydatid Disease in Iran, Kerman University of Medical Sciences, Kerman, Iran. ${ }^{5}$ Experimental Medicine Research Center, Tehran University of Medical Sciences, Tehran, Iran. ${ }^{6}$ Department of Pharmacology, School of Medicine, Tehran University of Medical Sciences, Tehran, Iran.

Received: 5 November 2020 Accepted: 17 March 2021

Published online: 12 April 2021

\section{References}

1. McManus DP, Zhang W, Li J, Bartley PB. Echinococcosis Lancet. 2003;362:1295-304.

2. World Health Organization. Echinococcosis. 2020.https://who.int/en/ news-room/fact-sheets/detail/echinococcosis. Accessed 23 March 2020.

3. Brunetti E, Kern P, Vuitton DA. Expert consensus for the diagnosis and treatment of cystic and alveolar echinococcosis in humans. Acta Trop. 2010;114:1-16.

4. Arif SH, Shams UI B, Wani NA, Zargar SA, Wani MA, Tabassum R, et al. Albendazole as an adjuvant to the standard surgical management of hydatid cyst liver. Int J Surg. 2008;6:448-51.

5. Junghanss T, da Silva AM, Horton J, Chiodini PL, Brunetti E. Clinical management of cystic echinococcosis: state of the art, problems, and perspectives. Am J Trop Med Hyg. 2008;79:301-11.

6. Panic G, Duthaler U, Speich B, Keiser J. Repurposing drugs for the treatment and control of helminth infections. Int J Parasitol Drugs Drug Resist. 2014;4:185-200.

7. Wolf $\mathrm{H}$. Preclinical and clinical pharmacology of the $5-\mathrm{HT}_{3}$ receptor antagonists. Scand J Rheumatol Suppl. 2000;113:37-45.

8. Rahimian R, Dehpour AR, Fakhfouri G, Khorramizadeh MR, Ghia JE, Seyedabadi $M$, et al. Tropisetron upregulates cannabinoid $C_{1}$ receptors in cerebellar granule cells: possible involvement of calcineurin. Brain Res. 2011;1417:1-8

9. Vega Lde L, Munoz E, Calzado MA, Lieb K, Candelario-Jalil E, Gschaidmeir $\mathrm{H}$, et al. The $5-\mathrm{HT}_{3}$ receptor antagonist tropisetron inhibits $\mathrm{T}$ cell activation by targeting the calcineurin pathway. Biochem Pharmacol. 2005;70:369-80.

10. Rusnak F, Mertz P. Calcineurin: form and function. Physiol Rev. 2000;80:1483-521.

11. Roy J, Cyert MS. Identifying new substrates and functions for an old enzyme: calcineurin. Cold Spring Harb Perspect Biol. 2020;12(3):a035436.

12. Roberts HC, Sternberg JM, Chappell LH. Characterization of calcineurin from Hymenolepis microstoma and $\mathrm{H}$. diminuta and its interaction with cyclosporin A. Parasitology. 1997;114(Pt 3):279-83.

13. Mecozzi B, Rossi A, Lazzaretti P, Kady M, Kaiser S, Valle C, et al. Molecular cloning of Schistosoma mansoni calcineurin subunits and immunolocalization to the excretory system. Mol Biochem Parasitol. 2000;110:333-43.

14. Nicolao MC, Cumino AC. Biochemical and molecular characterization of the calcineurin in Echinococcus granulosus larval stages. Acta Trop. 2015;146:141-51

15. Wang N, Zhong X, Song X, Gu X, Lai W, Xie Y, et al. Molecular and biochemical characterization of calmodulin from Echinococcus granulosus. Parasites Vectors. 2017;10:597.

16. Mousavi SM, Afgar A, Mohammadi MA, Mortezaei S, Sadeghi B, Harandi MF. Calmodulin-specific small interfering RNA induces consistent expression suppression and morphological changes in Echinococcus granulosus. Sci Rep. 2019;9:3894.

17. Friedberg F, Rhoads AR. Evolutionary aspects of calmodulin. IUBMB Life. 2001;51:215-21.

18. Gregory RE, Ettinger DS. 5-HT3 receptor antagonists for the prevention of chemotherapy-induced nausea and vomiting. A comparison of their pharmacology and clinical efficacy. Drugs. 1998;55:173-89.

19. Cen J, Wang M, Jiang G, Yin Y, Su Z, Tong L, et al. The new immunosuppressant, isogarcinol, binds directly to its target enzyme calcineurin, unlike cyclosporin A and tacrolimus. Biochimie. 2015;111:119-24.

20. Flores C, Fouquet G, Moura IC, Maciel TT, Hermine O. Lessons to learn from low-dose cyclosporin-a: a new approach for unexpected clinical applications. Front Immunol. 2019;10:588.

21. Colebrook AL, Jenkins DD, Lightowlers MW. Anti-parasitic effect of cyclosporin A on Echinococcus granulosus and characterization of the associated cyclophilin protein. Parasitology. 2002;125:485-93.

22. Horton RJ. Albendazole in treatment of human cystic echinococcosis: 12 years of experience. Acta Trop. 1997;64:79-93.

23. Smyth JD, Barrett NJ. Procedures for testing the viability of human hydatid cysts following surgical removal, especially after chemotherapy. Trans R Soc Trop Med Hyg. 1980;74:649-52.

24. Bowles J, Blair D, McManus DP. Genetic variants within the genus Echinococcus identified by mitochondrial DNA sequencing. Mol Biochem Parasitol. 1992;54:165-73.

25. Naguleswaran A, Spicher M, Vonlaufen N, Ortega-Mora LM, Torgerson $\mathrm{P}$, Gottstein $\mathrm{B}$, et al. In vitro metacestodicidal activities of genistein and other isoflavones against Echinococcus multilocularis and Echinococcus granulosus. Antimicrob Agents Chemother. 2006;50:3770-8.

26. Cevallos AM, Herrera J, Lopez-Villasenor I, Hernandez R. Differential effects of two widely used solvents, dmso and ethanol, on the growth and recovery of Trypanosoma cruzi epimastigotes in culture. Korean J Parasitol. 2017;55:81-4

27. Elissondo M, Dopchiz M, Ceballos L, Alvarez L, Sanchez Bruni S, Lanusse C, et al. In vitro effects of flubendazole on Echinococcus granulosus protoscoleces. Parasitol Res. 2006;98:317-23.

28. Tsai IJ, Zarowiecki M, Holroyd N, Garciarrubio A, Sanchez-Flores A, Brooks $\mathrm{KL}$, et al. The genomes of four tapeworm species reveal adaptations to parasitism. Nature. 2013;496:57-63.

29. Zheng H, Zhang W, Zhang L, Zhang Z, Li J, Lu G, et al. The genome of the hydatid tapeworm Echinococcus granulosus. Nat Genet. 2013:45:1168-75.

30. Dezaki ES, Yaghoubi MM, Spiliotis M, Boubaker G, Taheri E, Almani PG, et al. Comparison of ex vivo harvested and in vitro cultured materials from Echinococcus granulosus by measuring expression levels of five genes putatively involved in the development and maturation of adult worms. Parasitol Res. 2016;115:4405-16. 
31. Camicia F, Herz M, Prada LC, Kamenetzky L, Simonetta SH, Cucher MA, et al. The nervous and prenervous roles of serotonin in Echinococcus spp. Int J Parasitol. 2013:43:647-59.

32. Colebrook AL, Jenkins DJ, Jones MK, Tatarczuch L, Lightowlers MW. Effect of cyclosporin A on the survival and ultrastructure of Echinococcus granulosus protoscoleces in vitro. Parasitology. 2004;129:497-504.

33. Cumino AC, Lamenza P, Denegri GM. Identification of functional FKB protein in Echinococcus granulosus: its involvement in the protoscolicidal action of rapamycin derivates and in calcium homeostasis. Int J Parasitol. 2010;40:651-61

34. Perez-Serrano J, Casado N, Denegri G, Rodriguez-Caabeiro F. The effects of albendazole and albendazole sulphoxide combination-therapy on Echinococcus granulosus in vitro. Int J Parasitol. 1994;24:219-24.

35. Urrea-Paris MA, Moreno MJ, Casado N, Rodriguez-Caabeiro F. In vitro effect of praziquantel and albendazole combination therapy on the larval stage of Echinococcus granulosus. Parasitol Res. 2000;86:957-64.

36. Morris DL, Richards KS, Clarkson MJ, Taylor DH. Comparison of Albendazole and Praziquantel therapy of Echinococcus granulosus in naturally infected sheep. Vet Parasitol. 1990;36:83-90.

37. Bygott JM, Chiodini PL. Praziquantel: neglected drug? Ineffective treatment? Or therapeutic choice in cystic hydatid disease? Acta Trop. 2009;111:95-101.

38. Levron C, Scholz T, Dezfuli BS. Ultrastructure of microtriches on the scolex of Cyathocephalus truncatus (Cestoda: Spathebothriidea). Folia Parasitol (Praha). 2008;55:309-12
39. Thompson RC, Reynoldson JA, Riddler CR. Praziquantel adversely affects protoscoleces of Echinococcus granulosus in vitro. J Helminthol. 1986;60:279-86.

40. de la Torre-Escudero E, Bennett APS, Clarke A, Brennan GP, Robinson MW. Extracellular vesicle biogenesis in helminths: more than one route to the surface? Trends Parasitol. 2016;32:921-9.

41. Laura C, Celina E, Sergio SB, Guillermo D, Carlos L, Luis A. Combined flubendazole-nitazoxanide treatment of cystic echinococcosis: Pharmacokinetic and efficacy assessment in mice. Acta Trop. 2015;148:89-96.

42. Zimmermann B, Walz B. Serotonin-induced intercellular calcium waves in salivary glands of the blowfly Calliphora erythrocephala. J Physiol. 1997;500(Pt 1):17-28.

43. Heindorff K, Baumann O. Calcineurin is part of a negative feedback loop in the $\mathrm{Ins}_{3} / \mathrm{Ca}^{(2+)}$ signalling pathway in blowfly salivary glands. Cell Calcium. 2014;56:215-24.

44. Hoffman A, Taleski G, Sontag E. The protein serine/threonine phosphatases $P_{2} A_{1} P P_{1}$ and calcineurin: a triple threat in the regulation of the neuronal cytoskeleton. Mol Cell Neurosci. 2017;84:119-31.

45. Taman A, Azab M. Present-day anthelmintics and perspectives on future new targets. Parasitol Res. 2014;113:2425-33.

\section{Publisher's Note}

Springer Nature remains neutral with regard to jurisdictional claims in published maps and institutional affiliations.
Ready to submit your research? Choose BMC and benefit from:

- fast, convenient online submission

- thorough peer review by experienced researchers in your field

- rapid publication on acceptance

- support for research data, including large and complex data types

- gold Open Access which fosters wider collaboration and increased citations

- maximum visibility for your research: over $100 \mathrm{M}$ website views per year

At BMC, research is always in progress.

Learn more biomedcentral.com/submissions 